\title{
Are Preferences for Women's Hair Color Frequency-Dependent?
}

\author{
Zinnia J. Janif • Robert C. Brooks • \\ Barnaby J. Dixson
}

Received: 28 June 2014 / Revised: 5 September 2014 / Accepted: 10 September 2014 / Published online: 19 September 2014 (C) Springer International Publishing 2014

\begin{abstract}
An individual's fitness depends not only on their phenotype but also on the phenotypes of their competitors and contemporaries. Sexual attractiveness may be strongly influenced by an individual's familiarity to potential mates or the rarity of the individual's phenotype. Such effects can cause negative frequency-dependent selection, maintaining striking polymorphisms in ornamentation. Here we test whether preferences for women's hair color, which is highly polymorphic between European populations, reflects patterns of positive or negative frequency-dependence. We assigned each participant to one of four experimental treatments in which we manipulated the frequency of hair colors in a set of 18 images presented consecutively. The four treatments were: blond hair rare, brown hair rare, red hair rare and an even distribution of the three hair colors. Following immediately on from this experimental phase, participants rated the same set of 9 faces, 3 with each hair color. Results showed that the experimental manipulation of hair color frequency did not significantly influence hair-color attractiveness. However, there were sex differences in ratings: men rated blond hair as most sexually attractive and women rated both blond and brown hair equally as attractive as red hair. Self-reported natural hair color had weak but significant effects on hair color preferences, but these effects disappeared when we restricted analyses to participants of European descent only. Our findings do not support the hypothesis that men's preferences for women's hair color are negative frequencydependent, favoring rare hair colors.
\end{abstract}

Keywords Hair color - Attractiveness $\cdot$ Frequency-dependence $\cdot$ Sexual selection · Human evolution

Electronic supplementary material The online version of this article (doi:10.1007/s40750-014-0008-y) contains supplementary material, which is available to authorized users.

Z. J. Janif $\cdot$ R. C. Brooks $\cdot$ B. J. Dixson $(\triangle)$

Evolution \& Ecology Research Centre, School of Biological, Earth \& Environmental Sciences, The

University of New South Wales, Kensington, Sydney 2052 NSW, Australia

e-mail: b.dixson@unsw.edu.au 


\section{Introduction}

The maintenance of variation in attractive traits within a population has been long debated among evolutionary ecologists as the 'paradox of the lek' (Kirkpatrick and Ryan 1991; Andersson 1994; Hine, Chenoweth, and Blows 2004). If attractive ornaments signal underlying genetic quality, it would be reasonable to assume that preferences would converge on a single 'best' phenotype. However, this would ultimately deplete genetic variation in both quality and ornament, reducing any genetic benefits of mate choice. And yet sexually selected traits typically show some of the highest levels of additive genetic variance (Bakker and Pomiankowski 1995; Rowe and Houle 1996).

Although preferences for some traits may be absolute, an individual's attractiveness can depend on both their own phenotype and on the distribution of phenotypes of their competitors and contemporaries (Hughes et al. 1999; Kokko, Jennions, and Houde 2007). In guppies (Poecilia reticulata) polymorphic colouration is found almost exclusively in males (Houde 1997). Males bearing rare colour patterns have greater survivability in the wild (Olendorf et al. 2006) and greater mating success in the lab (Farr 1977; Hughes et al. 1999) and the wild (Hughes et al. 2013). Female guppies prefer males bearing novel (Hughes et al. 1999) or rare ornamental colour patterns (Zajitschek and Brooks 2008), and avoid mating with familiar-looking males or previous mates (Rosenqvist and Houde 1997; Kelley et al. 1999). Each of these processes can generate negative frequency-dependent sexual selection, and the presence of such comprehensive negative frequency dependent selection, which prevents the loss of rare colour pattern alleles, may explain the maintenance of the striking genetic polymorphism in male colour patterns.

In humans, polymorphisms within the melanocortin 1 receptor (MC1R) gene are responsible for variation in the production of eumelenin (brown and black pigments) and pheomelenin (red and yellow pigments), resulting in marked differences between populations in skin and hair colour (Liu, Wen, and Kayser 2013). Skin is darkest at tropical equatorial latitudes where ultra-violet (UV) rays are strongest, becoming lighter at more temperate Northern latitudes (Jablonski and Chaplin 2010). As humans settled in temperate European climates 35,000 years ago, the protective advantage of more melanic skin against UV diminished with selection favouring lighter skin pigmentation (Jablonski and Chaplin 2010; Liu et al. 2013). Selective sweeps for the KITLG gene shared by Europeans and Asians began 30,000 years ago, and selective sweeps for alleles within three genes (TYRP1, SLC4A5, and SLC45A2) specific to lighter skin in Europeans occurred between 11,000 and 19,000 years ago (Beleza et al. 2013) and 6,500-4,000 years ago (Wilde et al. 2014). UV is also synthesised into Vitamin D (VD) via the skin, which is key for a variety of biological processes, including foetal bone development (Robins 1991). Lighter skin in more temperate climates may have evolved to maximise VD synthesis within environments with lower UV, especially in women to facilitate augmented UV synthesis into VD during pregnancy (Jablonski and Chaplin 2000). Sexual dimorphism in skin complexion may have been further elaborated upon by sexual selection as lighter skin became associated with female reproductive success (Aoki 2002). Interestingly, while there is some ethnographic support for light skin being associated with feminine beauty (Van den Berghe and Frost 1986), skin reflectance is not more sexually dimorphic in populations with lower UV (Madrigal and Kelly 2007). Men's preferences for light skin in women are high in China 
(Dixson et al. 2007a; Swami et al. 2008), moderate in the U.S.A, New Zealand, and Papua (Dixson et al. 2010; Sorokowski, Sorokowska, and Kras 2013) and equivocal in Cameroon (Dixson et al. 2007b). Thus, light skin in women may have evolved primarily via natural selection and been subsequently elaborated upon, in some cultures, via sexual selection.

Environmental and ecological factors may explain variation in skin pigmentation as humans migrated out of Africa into Europe. However, hair pigmentation does not vary latitudinally in anything like the manner of skin pigmentation (Wilde et al. 2014). Instead scalp hair color is polymorphic across Africa (Jablonski and Chaplin 2014) and especially in Europe (Frost 2006), where multiple variants in alleles within the MC1R gene contribute to diversity in blond, brown, and red hair (Liu, Wen, and Kayser 2013). Although the timing of genetic variation in the MC1R gene and its relation to hair color polymorphisms remains to be determined (Frost 2014), had hair colour diversity in Europe been the result of relaxed selection, wherein the constraints of high UV drove selection on more eumelenin pigmentation, estimates of ancestral hair colour reaching present-day levels of diversity are between 850,000 and 1 million years (Frost 2006; Harding et al. 2000; Templeton 2002). Frost (2006) suggested that since humans settled in Europe only 35,000 ago the high variability in blond, brown, and red hair between European populations reflects rapid mutations occurring as small founder populations separated from parent populations and dispersed across Europe. Frost (2006) hypothesized that at this time male mortality was potentially higher due to male-male competition and longer hunting distances, which resulted in a greater number of females in the mating pool. This may have provided the conditions wherein mutations affecting the high variability in blond, brown, and red hair between European populations potentially spread, geographically, from where they first arose, via negative frequency-dependent sexual selection for rare hair colors (Frost 2006; 2014).

Globally the rates of naturally occurring blond hair are approximately $2 \%$ compared with over $90 \%$ dark hair (Gray 2008). The scant information for red hair suggests rates as low as $1 \%$ (Heckert and Best 1997) or $10 \%$ in some populations in Europe (Gray 2008). Unlike skin color, hair color likely has less influence on health and survival so that frequency dependent preferences for hair color may operate at proximate rather than ultimate levels. Indeed, Schweder (1994) reported that when women alter their hair color, they are more likely to change from one that is common to one that is rarer. Although such cosmetic alterations cannot alter the genetic basis of preferences, if women dye their hair to a color in order to be distinctive, that could confer a 'rarecolor' advantage to rare hair tones, potentially resulting in negative frequencydependent preferences for hair color in men (Frost 2006).

Blond hair appears more frequently in popular U.S media sources such as the Ladies' Home Journal, Vogue and Playboy than is typical for the base rate of blond hair in that population and most frequently in Playboy than the other magazines analysed, suggesting that blondness is associated with beauty and sexual attractiveness (Rich and Cash 1993). Compared to women with dark hair, blond haired women are approached more often by men in nightclubs and receive higher tips as waitresses (Guéguen 2012a, 2012b; Lynn 2009; Swami and Barrett 2011). While it is unknown whether the alleles associated with hair color diversification are sex-linked (Frost 2006), women's hair is lighter in early adulthood and becomes progressively darker as women age (Hinsz, et al. 2001). In addition to being a cue of youth, blond hair may 
be sexually attractive to men because it becomes easier to gauge infectious diseases and intestinal infections such as anemia, cyanosis, and jaundice among blond haired women who tend to have lighter skin than among women with brown hair with more melanic complexions that may mask conditions that present cutaneously (Ramachandran 1997).

Men's preferences for women's hair color in experimental studies are, however, mixed. In some studies blond hair was rated most attractive (Sorokowski 2006), while in others blond hair was rated as younger and healthier, but not more attractive than brown hair (Matz and Hinsz 2000; Sorokowski 2008). Elsewhere, blonds were judged as less attractive and more sexually promiscuous than women with brown hair (Swami, Furnham, and Joshi 2008). And other studies have reported that brown hair was more attractive than blond hair (Swami and Barrett 2011; Verweij, Burri, and Zietsch 2012), including a cross-cultural study where brown hair was more attractive than blond hair in six out of eight cultures (Swami et al. 2008). These equivocal findings might simply reflect culturally variable tastes with different samples expressing geographically or spatially different mean preferences. However, given the cross-cultural variation in hair color, variable preferences might also reflect a frequency-dependent dimension to men's preferences (Frost 2006). Such frequency-dependence could be operating within experiments, within societies sampled in those studies, or both.

One way to test whether preferences are frequency-dependent is via manipulative experiments. Brief exposure to visual stimuli can illicit domain-specific responses that are relevant in mate selection. For example, exposure to photographs of physically attractive same-sex targets lowered women's self-perceived attractiveness whereas men's self-perceived attractiveness was lower following exposure to stimuli of men of higher social dominance (Gutierres, Kenrick, and Partch 1999). However, face preferences may also reflect more domain-general effects of learning so that familiarity with facial stimuli drives convergence in preferences. Thus, Principe and Langlois (2012) assigned participants to rate 15 human faces, 15 faces of chimpanzees or 15 faces that were morphed to be $60 \%$ human and $40 \%$ chimpanzee. Individuals familiarised to human-chimp morphs gave higher ratings to human-chimp morphed faces than participants exposed to other conditions. Attractiveness ratings for sex typical facial shapes are also higher following exposure to similar looking faces than prior to exposure (Little, DeBruine, and Jones 2005). However, following experimental manipulations to be more or less familiar with a given set of faces men rated novel female faces as more attractive (Little, Debruine, and Jones 2014). Interestingly, both men and women exposed to 24 faces depicting either clean-shaven faces, fully bearded faces or a mixture of bearded, stubbled or clean-shaven faces, rated full beards and clean-shaven faces as more attractive when they were rare than when they common (Janif, Brooks, and Dixson 2014). These studies demonstrate that brief exposure to facial stimuli can induce directional shifts in face preferences that, in some cases, may reflect frequency-dependence effects on preferences.

Where women's hair colour is concerned effects of frequency-dependence on men's preferences for hair colors are inconclusive. In one study, Thelen (1983) manipulated the ratio of blond to brown haired women to test the effect of rarity on hair color preferences using three experimental treatments wherein participants rated a brown hair model alone, alongside 5 blond models, and alongside 11 blond models. The same procedure was also undertaken for a blond target model presented alongside brown haired models. Results showed that brown hair was progressively more attractive as 
brown hair became rarer but the same pattern was not observed for blond hair (Thelen 1983). Hinsz et al. (2013) measured preferences for hair color against the frequency of hair color using written questionnaires conducted in two samples from Northern and Southern prairies in North Dakota, U.S.A. They found positive selection for brown hair when brown hair was common in the population. Thus, whether men's preferences for female hair colour reflect positive or negative frequency-dependence requires further exploration.

To this end, using experimental procedures employed in more recent studies of face preferences (Janif et al. 2014; Little et al. 2014; Principe and Langlois 2012) we tested whether preferences shift away from a central tendency to prefer common hair colors towards rarer hair colors following experimentally familiarising participants to specific hair colors. We predicted that men's preferences for women's hair color would reflect negative frequency-dependent patterns, especially for blond and red hair, given their typically low rates cross-culturally (Gray 2008; Heckert and Best 1997). We placed participants into experimental treatments wherein the frequency of women's hair color varied and compared exposure to different treatments with responses to a standard set of stimuli that varied in brown, blond, and red hair. Our primary aim was to test whether the attractiveness of women's hair color reflects patterns of negative frequency-dependence, so that hair colors become more attractive when rare than when common. However, men's preferences for women's hair colour are also dependent on homogamy, the degree to which a potential mate bears self-resembling characteristics, and their partners hair color (Bovet et al. 2012; Hinsz et al. 2013). Thus, we tested whether women's self-rated hair-color and men's partners natural hair color were associated with frequency-dependent preferences for hair color.

\section{Materials and Methods}

\section{Stimuli}

Twelve female models were freely available from www.dailymakeover.com to which over 2,000 hairstyles and 32 colours could be applied. From the available hairstyles we selected only those with straight hair that did not obscure the face (e.g. fringes dropping over the face), resulting in 72 hairstyles. Six hairstyles were selected from the total pool of 72 and randomly assigned to each of the twelve model faces. We then generated a realistic set of blond, brown, and red hair colours by first eliminating from the 32 available hair colours all the unnatural colours (e.g. bright blue, purple, neon colours and bleached blonds). Our final sample included 2 blond, 2 brown and 2 red hair colours, one assigned to each of the six hairstyles resulting in 12 images for each hair colour category.

\section{Procedure}

This study was completed on-line at www.socialsci.com. Participants were recruited through social media outlets (e.g. Facebook), volunteered to rate women's faces for attractiveness, and were randomly assigned by the software running the experiment to one of the four treatments (rare blond, rare brown, rare red, and an even treatment). 
However, due to an error in the programming the 'brown rare' treatment had to be run separately via an additional web-link, which explains the discrepancies in the sample sizes between treatments. The web link was advertised via the same outlets and therefore there were no systematic differences in the source of sampling for this treatment compared to other treatments. Participants viewed two consecutive sets of stimuli. The first familiarized them with a set of 18 faces corresponding to the treatment to which they were assigned. The second presented a standardized set of 9 faces to gauge the attractiveness of women's hair color; these ratings are the data we analyze. From the subject's point of view there was no obvious transition between the stimulus sets - they simply rated 27 consecutive images for attractiveness.

From the 12 available models 9 models in each of three hair color conditions (blond, brown, and red) were used to populate the four experimental treatments. The 'rare blond' treatment included all nine brown hair and all nine red heads; the 'rare brown' treatment presented all nine blonds and all nine red heads; the 'rare red' treatment included all nine blond and all nine brown haired stimulus and the 'even treatment' included six models of each hair colour, drawn at random. Images were presented in random order, and participants rated each face for sexual attractiveness using a Likert scale where $-4=$ Very unattractive -+4 very attractive.

To quantify preferences for women's hair color we measured participant's response to a standard set of 9 faces, following directly on from the experimental treatment. The standardized set comprised the remaining 3 models of each hair colour, each of whom were of European descent (Fig. 1). Each model was presented with brown, red and blond hair, resulting in 9 stimuli, presented in a randomised sequence and rated using the same Likert scale as above.

After completing the ratings, participants provided information regarding their relationship status, sexual orientation, their own and their partners' natural hair color. This study was approved by the Human Ethics Committee at the University of New South Wales (HREC \#1878).

Effects of Sex, Treatment, and Participant Self-Reported Hair Color on Attractiveness Judgments of Women's Hair Color

\section{Participants}

A total of 2,152 (mean age $\pm S D=26.44 \pm 8.23$ years) participants of which 1,494 female (25.95 \pm 7.76 years) and 658 males (27.57 \pm 9.10 years) completed this study.

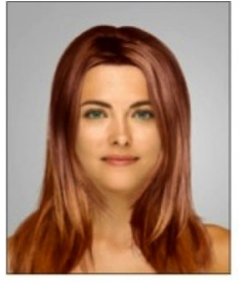

Red

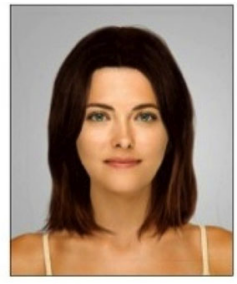

Brown

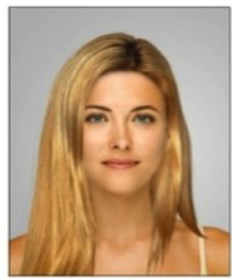

Blond

Fig. 1 Examples of the stimuli used in the current study. Images show the same woman with red, brown, and, blond hair 
Only heterosexual or bisexual participants (Kinsey scale 0-3; Kinsey, Pomeroy, and Martin 1948) responses were included of which only 82 (3.8\%) were bi-sexual. Thus, homosexual participants (Kinsey scale 4-6) were excluded from the analyses. Our sample comprised people of both European descent $(n=1,430 ; 66.4 \%)$ and nonEuropean descent $(n=722 ; 33.6 \%)$. Ethnicities among participants of non-European descent were as follows: $44.4 \%$ Asian, $3.4 \%$ North African/Middle Eastern Jewish or Arabic; $2.5 \%$ other North African/Middle Eastern; $0.7 \%$ West/Central/Southern African; $7.5 \%$ Native Australasian and Pacific islanders, $4.6 \%$ Native North American, $14.7 \%$ Central/South American, $2.5 \%$ Caribbean islanders and $19.7 \%$ stated no ethnic group. Our stimuli were of European faces and hair color preferences vary crossculturally (Swami et al. 2008), thus we included ethnicity (European or non-European) categories in our analyses. Sample sizes and ages $( \pm 1 \mathrm{SD})$ for each treatment split by sex and ethnicity are shown in Table 1.

\section{Statistical Analyses}

Attractiveness ratings for facial stimuli showed good internal reliability among the total sample $(\alpha=0.855)$ as well as within men $(\alpha=0.855)$ and women $(\alpha=0.851)$ analysed separately. Thus, average attractiveness ratings within each hair color category were dependent variables in a repeated-measures ANOVA where hair colour (brown, blond, and red) was the within-subjects fixed-factor and treatment (rare blond, rare brown, rare red, and even), own hair colour (blond, brown, red), sex (male, female) and ethnicity (European, non-European) were between-subjects factors.

\section{Results}

There was a significant main effect of hair colour (Table 2), such that blond and brown hair were more attractive than red hair (all $t_{2151} \geq 22.09$, all $\left.p<0.001\right)$, but differences between brown and blond hair were non-significant $\left(t_{2151}=0.86, p=0.388\right)$. There was a significant hair color $\times$ sex interaction (Table 2 ). Men gave higher ratings for blond hair than brown and red hair (all $\mathrm{t}_{657} \geq 4.57$, all $p<0.001$ ) and higher ratings to brown hair than red heads $\left(\mathrm{t}_{657}=6.77, p<0.001\right)$. Women gave higher ratings to brown hair than blond and red hair (all $t_{1493} \geq 4.18$, all $p<0.001$ ), blond hair was more attractive

Table 1 Sample sizes and mean ages $( \pm 1 \mathrm{SD})$ for the analyses of the total sample including men and women or both European and non-European descent

\begin{tabular}{|c|c|c|c|c|}
\hline \multirow[b]{2}{*}{ Treatment } & \multicolumn{2}{|l|}{ Male } & \multicolumn{2}{|l|}{ Female } \\
\hline & European & Non-European & European & Non-European \\
\hline Even & $55(30.87 \pm 11.21)$ & $47(24.96 \pm 5.40)$ & $126(27.29 \pm 7.55)$ & $62(24.97 \pm 6.47)$ \\
\hline Rare blond & $57(29.68 \pm 10.90)$ & $49(25.73 \pm 4.51)$ & $154(27.04 \pm 8.27)$ & $77(25.36 \pm 7.54)$ \\
\hline Rare brown & $223(28.93 \pm 10.83)$ & $104(24.68 \pm 6.96)$ & $638(26.46 \pm 8.24)$ & $238(24.45 \pm 7.08)$ \\
\hline Rare red & $62(27.81 \pm 6.68)$ & $61(25.82 \pm 5.95)$ & $115(25.65 \pm 7.03)$ & $84(23.94 \pm 6.12)$ \\
\hline
\end{tabular}


than red hair $\left(\mathrm{t}_{1493}=20.11, p<0.001\right)$ and gave higher ratings than men for brown, blond, and red hair (all $t_{2150} \geq 3.92$, all $p<0.001$ ) (Fig. 2).

There was also a significant hair color $\times$ sex $\times$ ethnicity interaction (Table 2). Comparisons within participants of European ethnicity revealed that men rated brown and blond hair as more attractive than red hair (all $t_{396} \geq 6.91$, all $p<0.001$ ), but

Table 2 Repeated-measures ANOVA on the effects of hair color, treatment, self-reported hair colour, and sex on attractiveness ratings. Data in bold are those retained in the final model

Within-subjects effects

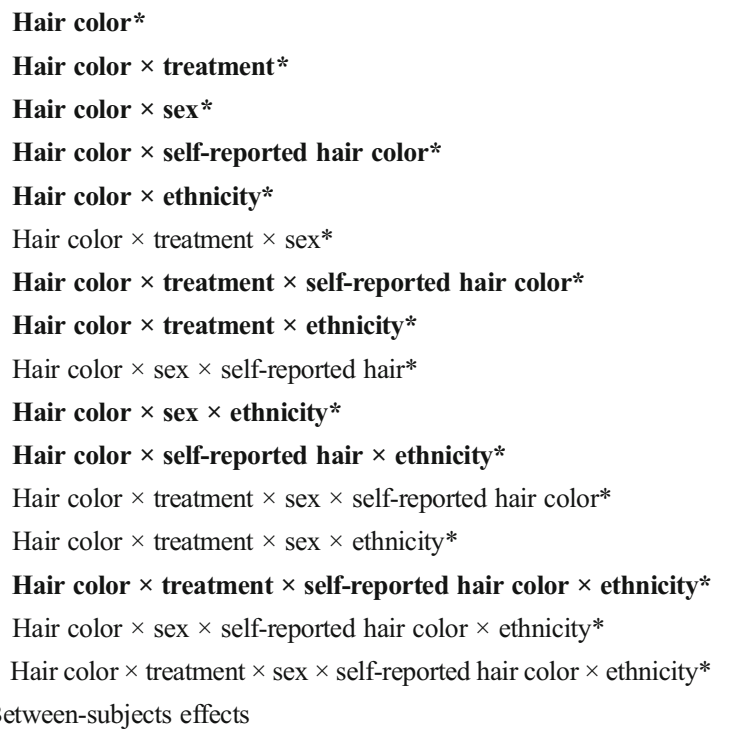

Between-subjects effects

\begin{tabular}{rrrr}
\multicolumn{1}{c}{$F$} & \multicolumn{1}{c}{$d f$} & \multicolumn{1}{c}{$P$} & \multicolumn{1}{c}{$\eta_{p}{ }^{2}$} \\
$\mathbf{3 2 . 8 4}$ & $\mathbf{2 . 0 ,} \mathbf{4 1 7 5 . 1}$ & $<\mathbf{0 . 0 0 1}$ & $\mathbf{0 . 0 1 5}$ \\
$\mathbf{0 . 6 2}$ & $\mathbf{5 . 9}, \mathbf{4 1 7 5 . 1}$ & $\mathbf{0 . 7 1 2}$ & $\mathbf{0 . 0 0 1}$ \\
$\mathbf{3 1 . 7 0}$ & $\mathbf{2 . 0 ,} \mathbf{4 1 7 5 . 1}$ & $<\mathbf{0 . 0 0 1}$ & $\mathbf{0 . 0 1 5}$ \\
$\mathbf{0 . 2 7}$ & $\mathbf{3 . 9}, \mathbf{4 1 7 5 . 1}$ & $\mathbf{0 . 8 9 4}$ & $<\mathbf{0 . 0 0 1}$ \\
$\mathbf{0 . 7 9}$ & $\mathbf{2 . 0 ,} \mathbf{4 1 7 5 . 1}$ & $\mathbf{0 . 4 5 2}$ & $<\mathbf{0 . 0 0 1}$ \\
1.52 & $5.9,4170.5$ & 0.168 & 0.002 \\
$\mathbf{1 . 2 5}$ & $\mathbf{1 1 . 8 , 4 1 7 5 . 1}$ & $\mathbf{0 . 2 4 1}$ & $\mathbf{0 . 0 0 4}$ \\
$\mathbf{1 . 3 0}$ & $\mathbf{5 . 9}, \mathbf{4 1 7 5 . 1}$ & $\mathbf{0 . 2 5 6}$ & $\mathbf{0 . 0 0 2}$ \\
0.64 & $3.9,4166.9$ & 0.634 & 0.001 \\
$\mathbf{3 . 8 8}$ & $\mathbf{2 . 0 ,} \mathbf{4 1 7 5 . 1}$ & $\mathbf{0 . 0 2 1}$ & $\mathbf{0 . 0 0 2}$ \\
$\mathbf{1 . 3 9}$ & $\mathbf{3 . 9}, \mathbf{4 1 7 5 . 1}$ & $\mathbf{0 . 2 3 5}$ & $\mathbf{0 . 0 0 1}$ \\
0.59 & $11.8,4151.6$ & 0.846 & 0.002 \\
0.28 & $5.9,4145.3$ & 0.946 & $<0.001$ \\
$\mathbf{2 . 0 0}$ & $\mathbf{1 1 . 8 , 4 1 7 5 . 1}$ & $\mathbf{0 . 0 2 1}$ & $\mathbf{0 . 0 0 6}$ \\
1.23 & $3.9,4163.0$ & 0.341 & 0.001 \\
1.35 & $5.9,4139.4$ & 0.233 & 0.002
\end{tabular}

$\begin{array}{lrrrr}\text { Treatment } & \mathbf{0 . 8 9} & \mathbf{3 , 2 1 2 6} & \mathbf{0 . 4 4 7} & \mathbf{0 . 0 0 1} \\ \text { Sex } & \mathbf{4 1 . 3 7} & \mathbf{1 , 2 1 2 6} & <\mathbf{0 . 0 0 1} & \mathbf{0 . 0 1 9} \\ \text { Self-reported hair color } & \mathbf{0 . 0 3} & \mathbf{2 , 2 1 2 6} & \mathbf{0 . 9 7 1} & <\mathbf{0 . 0 0 1} \\ \text { Ethnicity } & \mathbf{5 . 0 5} & \mathbf{1 , 2 1 2 6} & \mathbf{0 . 0 2 5} & \mathbf{0 . 0 0 2} \\ \text { Treatment } \times \text { sex } & 0.78 & 3,2123 & 0.507 & 0.001 \\ \text { Treatment } \times \text { self-reported hair color } & \mathbf{0 . 3 8} & \mathbf{6 , 2 1 2 6} & \mathbf{0 . 8 9 3} & \mathbf{0 . 0 0 1} \\ \text { Treatment } \times \text { ethnicity } & \mathbf{1 . 6 0} & \mathbf{3 , 2 1 2 6} & \mathbf{0 . 1 8 6} & \mathbf{0 . 0 0 2} \\ \text { Sex } \times \text { self-reported hair color } & 2.28 & 2,2121 & 0.102 & 0.002 \\ \text { Sex } \times \text { ethnicity } & \mathbf{0 . 1 2} & \mathbf{1 , 2 1 2 6} & \mathbf{0 . 7 3 0} & <\mathbf{0 . 0 0 1} \\ \text { Self-reported hair color } \times \text { ethnicity } & \mathbf{1 . 1 5} & \mathbf{2 , 2 1 2 6} & \mathbf{0 . 3 1 7} & \mathbf{0 . 0 0 1} \\ \text { Treatment } \times \text { sex } \times \text { self-reported hair color } & 1.32 & 6,2113 & 0.247 & 0.004 \\ \text { Treatment } \times \text { sex } \times \text { ethnicity } & 1.15 & 3,2110 & 0.329 & 0.002 \\ \text { Treatment } \times \text { self-reported hair color } \times \text { ethnicity } & \mathbf{0 . 7 2} & \mathbf{6 , 2 1 2 6} & \mathbf{0 . 6 3 3} & \mathbf{0 . 0 0 2} \\ \text { Sex } \times \text { self-reported hair color } \times \text { ethnicity } & 0.88 & 2,2119 & 0.415 & 0.001 \\ \text { Treatment } \times \text { sex } \times \text { self-reported hair color } \times \text { ethnicity } & 0.18 & 3,2107 & 0.907 & <0.001\end{array}$

* Greenhouse - Geisser adjusted df (rounded to one decimal place) 


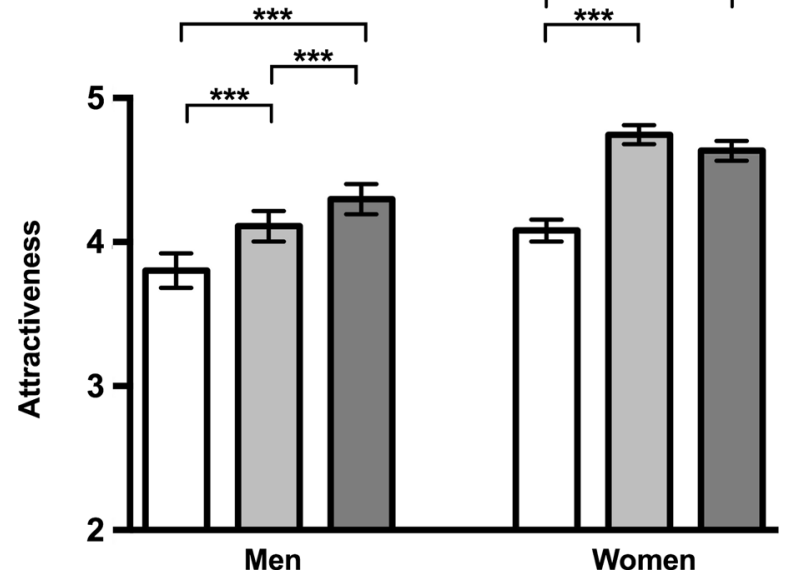

Fig. 2 Mean attractiveness ratings $( \pm 95 \% \mathrm{CI})$ for women's hair color (red, brown, and blond hair) split by sex of respondents (male or female). Data from the Likert scales were re-scaled for the Figure to reflect positive values by adding $4 . * * *=P<.001$

preferences for blond and brown hair did not differ significantly $\left(\mathrm{t}_{396}=1.19, p=0.236\right)$. Within women of European descent preferences were higher for brown hair than blond and red hair (all $\mathrm{t}_{1032} \geq 4.08$, all $p<0.001$ ), blond hair was also more attractive than red hair $\left(\mathrm{t}_{1032}=15.80, p<0.001\right)$. Within participants of European ethnicity women gave higher ratings than men for all three hair colours (all $\mathrm{t}_{1428} \geq 3.02$, all $p<0.01$ ). Comparisons within participants of non-European ethnicity revealed that men rated blond hair as more attractive than brown and red hair (all $\mathrm{t}_{260} \geq 5.70$, all $p<0.001$ ), and brown hair more attractive than red hair $\left(\mathrm{t}_{260}=2.12, p=0.035\right)$. Within women of non-European descent brown and blond hair were rated as more attractive than red hair (all $t_{460} \geq$ 12.42, all $p<0.001$ ), but preferences for blond and brown hair did not differ significantly $\left(\mathrm{t}_{460}=1.43, p=0.154\right)$. Among participants of non-European descent women gave higher ratings than men for blond, brown, and red hair (all $t_{720} \geq 2.34$, all $p<0.05$ ). Comparisons between ethnicities revealed that men of European descent grave higher ratings than men of non-European descent for brown hair $\left(\mathrm{t}_{656}=3.13\right.$, $p=0.002$ ), but not blond or red hair (all $t_{656} \leq 0.59$, all $p \geq 0.557$ ). Preferences between women of European and non-European ethnicity did not differ significantly for any hair colors (all $t_{1492} \leq 1.44$, all $p \geq 0.149$ ).

There was also significant hair color $\times$ treatment $\times$ own hair color $\times$ ethnicity interaction (Table 2). This reflects that a variable distribution between treatments among participants of non-European descent with self-reported red hair compared with participants of European descent with self-reported red hair (see Figures S1-S3 in the supplementary materials). However, given red hair among non-Europeans is unusual, as reflected in the low sample size $(n=14)$, we re-ran the analysis with this group 
removed and found this four-way interaction was no longer significant $\left(\mathrm{F}_{6.0,4158.2}=\right.$ $1.57, p=0.154, \eta_{p}{ }^{2}=0.002$ ). We thus limit our interpretation of this four-way interaction as we can attach little weight to this finding.

Given the significant effect of ethnicity on hair color preferences (Table 2), we re-ran the analyses to include only participants of European descent. Results showed a significant main effect of hair colour (Table 3), so that brown hair was more attractive than blond and red hair (all $\mathrm{t}_{1429} \geq 2.84$, all $p<0.01$ ) and blond hair was more attractive than red hair $\left(\mathrm{t}_{1429}=18.34, p<0.001\right)$. There was also a significant hair color $\times$ sex interaction (Table 3). Within men, preferences were higher for blond and brown hair over red hair (all $t_{396} \geq 6.91$, all $p<0.001$ ), but preferences between blond and brown hair did not differ significantly $\left(\mathrm{t}_{396}=1.19, p=0.236\right)$. Within women, preferences were higher for brown over blond and red hair (all $t_{1032} \geq 4.08$, all $p<0.001$ ), and blond hair was significantly more attractive than red hair $\left(\mathrm{t}_{1032}=15.80, p<0.001\right)$. Comparisons between the sexes revealed women gave higher ratings than men for brown, blond, and red hair (all $\mathrm{t}_{1428} \geq 3.02$, all $p<0.01$ ).

There was also a significant hair color $\times$ treatment $\times$ own hair color interaction (Table 3). Comparisons between participants according to self-reported hair color revealed that within the rare brown treatment, participants with red hair gave significantly higher ratings to stimuli with red hair than participants with brown $\left(\mathrm{t}_{565}=3.34\right.$, $p<0.001)$ or blond hair $\left(\mathrm{t}_{346}=3.37, p<0.001\right)$ gave (Fig. 3$)$. No other comparisons between participants according to self-rated hair color within this treatment were

Table 3 Repeated-measures ANOVA on the effects of hair color, treatment, self-rated hair color, and sex on attractiveness ratings among participants of European descent. Data in bold are those retained in the final model

\begin{tabular}{|c|c|c|c|c|}
\hline & $F$ & $d f$ & $P$ & $\eta_{p}^{2}$ \\
\hline Color* & 21.73 & $2.0,2754.5$ & $<0.001$ & 0.015 \\
\hline Color $\times$ treatment $*$ & 0.69 & $5.9,2754.5$ & 0.655 & 0.001 \\
\hline Color $\times$ sex* & 7.69 & $2.0,2754.5$ & $<0.001$ & 0.005 \\
\hline Color $\times$ self-rated hair color* & 2.02 & $3.9,2754.5$ & 0.091 & 0.003 \\
\hline Color $\times$ treatment $\times \operatorname{sex} *$ & 1.05 & $5.9,2754.5$ & 0.388 & 0.002 \\
\hline Color $\times$ treatment $\times$ self-rated hair color* & 1.95 & $11.7,2754.5$ & 0.026 & 0.008 \\
\hline Color $\times$ sex $\times$ self-rated hair color* & 1.07 & $3.9,2754.5$ & 0.369 & 0.002 \\
\hline Color $\times$ treatment $\times$ sex $\times$ self-rated hair color* & 0.64 & $11.7,2744.2$ & 0.808 & 0.003 \\
\hline \multicolumn{5}{|l|}{ Between-subjects effects } \\
\hline & $F$ & $d f$ & $P$ & $\eta_{p}^{2}$ \\
\hline Treatment & 0.25 & 3,1412 & 0.864 & 0.001 \\
\hline Sex & 15.57 & 1,1412 & $<0.001$ & 0.011 \\
\hline Self-rated hair color & 0.75 & 2,1412 & 0.475 & 0.001 \\
\hline Treatment $\times$ sex & 0.10 & 3,1412 & 0.963 & $<0.001$ \\
\hline Treatment $\times$ self-rated hair color & 1.05 & 6,1412 & 0.394 & 0.004 \\
\hline Sex $\times$ self-rated hair color & 2.82 & 2,1412 & 0.060 & 0.004 \\
\hline Treatment $\times$ sex $\times$ self-rated hair color & 0.91 & 6,1406 & 0.488 & 0.004 \\
\hline
\end{tabular}

* Greenhouse - Geisser adjusted df (rounded to one decimal place) 
statistically significant (all $\mathrm{t} \leq 1.80$, all $p \geq 0.072$ ). In the even treatment, participants with blond hair gave higher ratings than participants with brown hair for stimuli with blond and red hair (all $t_{173} \leq 1.98$, all $p<0.05$ ), but no other paired comparisons within this treatment were significant (all $\mathrm{t} \leq 1.83$, all $p \geq 0.070$ ). In the rare blond treatment, participants with red hair gave higher ratings than participants with blond hair for stimuli depicting blond hair (Levene's test $[F=4.95, p=0.029] ; \mathrm{t}_{21.742}=2.22, p=0.037$ ), but no other paired comparisons within this treatment were significant (all $t \leq 1.78$, all $p \geq 0.098$ ). No paired comparisons in the red rare treatment reached statistical significance (all $\mathrm{t} \leq 1.74$, all $p \geq 0.087$ ).

Effects of Treatment and Partners Hair Colour on Men's Preferences for Women's Hair Colour

We tested whether men's preferences for women's hair color were influenced by their partners hair color and whether such preferences influenced preferences between the different treatments of hair color frequency. From the total sample, 363 men (mean age \pm $S D=29.87 \pm 9.43$ years) were in relationships and reported the natural hair color of their partners. Of this sample, 229 (31.52 \pm 10.44 years) were men of European descent and 134 were of non-European descent ( $27.04 \pm 6.50$ years). Given the small sample of nonEuropean descent, we restricted our analyses to men of European descent. The sample sizes in each treatment split by the hair color of men's partners are shown in Table 4.

Attractiveness ratings for facial stimuli showed good internal reliability among participants $(\alpha=0.869)$. Thus, average attractiveness ratings within each category of hair color was entered as the dependent variable in a repeated-measures ANOVA where hair colour (brown, blond, and red) was the within-subjects fixed-factor and partners hair colour (blond, brown, red) and treatment (rare blond, rare brown, rare red, and even) were between-subjects factors. There was a significant main effect of hair colour (Table 5), so that blond and brown hair was more attractive than red hair (all $t_{228} \geq 5.03$, all $p<0.001$ ), but preferences for brown and blond hair did not differ significantly from one another $\left(\mathrm{t}_{228}=1.01, p=0.314\right)$. The ANOVA revealed no main effects or interactions involving hair color, treatment or partners hair colour (Table 5).

\section{Discussion}

Frost (2006) proposed that the rapid diversification and maintenance of polymorphisms in hair color among Europeans might be attributable to negative frequency-dependent sexual selection, wherein women bearing rare colors relative to their counterparts were historically preferred as mates. In the present study we tested whether experimentally manipulating the frequency of hair colors influenced the attractiveness of rare female hair colors. Overall, we found no evidence of negative frequency-dependence in men or women's preferences for women's hair color. There were subtle interactions between self-reported hair color, ethnicity, and treatment that were associated with hair color preferences. However, this interaction was driven by lower attractiveness ratings given by participants of non-European ethnicity with red hair. Given that this group represented only a small proportion of the total sample we re-analyzed the data after removing these participants, which revealed the interaction between ethnicity, self- 


\section{Ratings for blond hair}
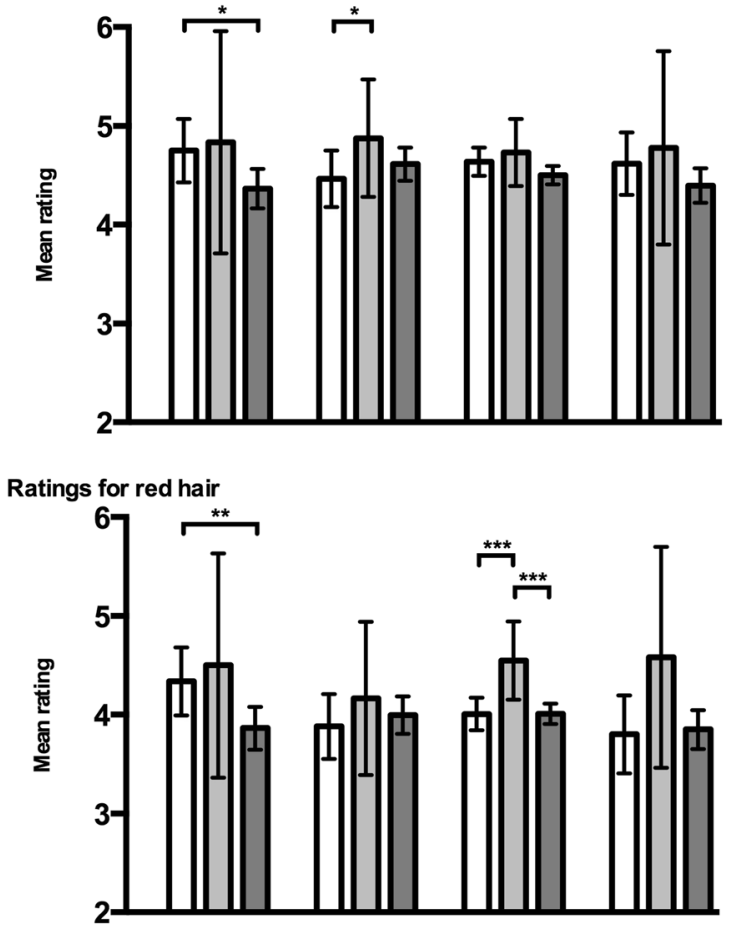

Self-rated hair color

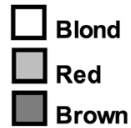

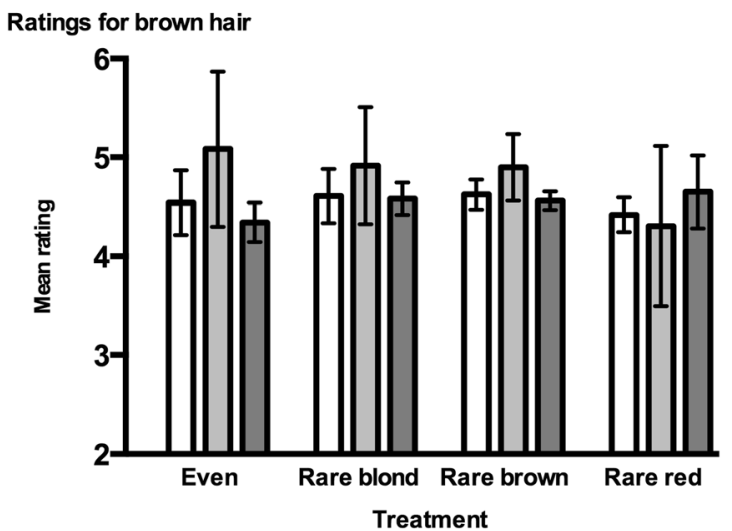

Fig. 3 Mean attractiveness $( \pm 95 \% \mathrm{CI}$ ) for blond, red, and brown hair split by participants selfreported hair color (red, brown, and blond hair) and experimental treatment (even, rare blond, rare brown, and rare red). Data from the Likert scales were re-scaled for the Figure to reflect positive values by adding $4 .{ }^{*}=P<.05 ; * *=P<.01 ; * * *=P<.001$

reported hair color, and treatment on hair color preferences to be no longer statistically significant. When we restricted our analyses to participants of European descent, we noted a significant interaction between self-reported hair color, treatment, and hair color preferences. However, this interaction was driven by participants with red hair giving higher attractiveness ratings to stimuli with red hair within the treatment in which 
Table 4 Sample sizes and mean ages $( \pm 1 \mathrm{SD})$ for analyses of the sub-sample of European men split by the hair color of their current partners and treatment

\begin{tabular}{lclr}
\hline & \multicolumn{2}{l}{ Partners hair color } & \\
\cline { 2 - 4 } Treatment & Blond & \multicolumn{1}{l}{ Brown } & \multicolumn{1}{l}{ Red } \\
\hline Even & $5(32.80 \pm 4.97)$ & $29(33.72 \pm 11.97)$ & $25.00 \pm 11.31)$ \\
Rare blond & $7(29.86 \pm 7.69)$ & $26(33.38 \pm 11.87)$ & $3(26.67 \pm 10.60)$ \\
Rare brown & $31(33.61 \pm 11.71)$ & $77(30.52 \pm 10.34)$ & $10(32.50 \pm 13.06)$ \\
Rare red & $9(31.56 \pm 8.79)$ & $27(29.15 \pm 6.97)$ & $3(27.33 \pm 4.16)$ \\
\hline
\end{tabular}

brown hair was rare (and blond and red hair more common). Thus, if anything, there may be limited positive frequency-dependent preferences among participants with red hair for common stimuli with red hair.

To our knowledge only two previous studies have tested whether men prefer rare hair colors in women. Thelen (1983) found using photographic stimuli that the attractiveness of brown hair increased as the frequency of blond hair increased and brown hair decreased, providing support for negative-frequency dependent preferences for brown hair. However, Hinsz et al. (2013) compared self-reported hair color and stated preferences for hair color in an ideal partner and found no effects of rarity on preferences for female hair color, instead brown hair was more attractive when brown hair were more common. Methods between these studies varied considerably. Thelen (1983) collected preference ratings for brown hair in photographic stimuli presented alone, alongside 5 blond females, and alongside 11 blond females. In contrast, Hinsz et al. (2013) compared stated hair color preferences collected via questionnaires against the self-reported hair color from the sampled population. In our study we employed an experimental design aimed at familiarizing participants with hair color by exposing participants to different treatments in which the frequency of hair color were manipulated relative to a response set of faces that was the same across all treatments. Thus, we

Table 5 Repeated-measures ANOVA on the effects of hair color, treatment, and partners hair color on attractiveness ratings among European participants

\begin{tabular}{llcll}
\hline Within-subjects effects & & & & \\
& $F$ & $d f$ & $P$ & $\eta_{p}{ }^{2}$ \\
Hair color* & 4.76 & $1.9,406.8$ & 0.010 & 0.021 \\
Hair color $\times$ treatment* & 0.30 & $5.6,406.8$ & 0.927 & 0.004 \\
Hair color $\times$ Partners hair color* & 0.79 & $3.7,406.8$ & 0.526 & 0.007 \\
Hair color $\times$ treatment $\times$ partners hair color* & 0.73 & $11.2,406.8$ & 0.710 & 0.020 \\
Between-subjects effects & & & & \\
& $F$ & $d f$ & $P$ & $\eta_{p}{ }^{2}$ \\
Treatment & 0.16 & 3,217 & 0.925 & 0.002 \\
Partners hair color & 0.18 & 2,217 & 0.835 & 0.002 \\
Treatment $\times$ Partners hair color & 0.63 & 6,217 & 0.706 & 0.017 \\
\hline
\end{tabular}

* Greenhouse - Geisser adjusted df (rounded to one decimal place) 
presented participants with treatments in which blond, brown, and red hair each had a treatment in which they were rare and a control treatment in which hair colors were equally represented. Similar techniques have been employed and found to induce positive effects of familiarization on faces preferences (Principe and Langlois 2012) and effects of rarity on faces preferences (Janif, Brooks, and Dixson 2014). However, we found no simple interaction with preferences for hair color and treatment. Thus, taken together our findings add to the equivocal patterns across past studies seeking to demonstrate whether men's preferences for women's hair color are modulated by the frequency of hair colors.

This is not to say that rarity has no influence on male face preferences. Our methods for familiarizing participants using 18 images in which some hair colors were common may simply not have been sufficient to generate the perception of rarity in other hair colors. Further, some model faces (but not the combination of face and hair color) were repeated within the familiarization phase of the experiment, which may have introduced noise during the ongoing task of rating the faces. The study was also conducted on-line and not under the controlled conditions of the lab where participants are free from distractions, which may also have impacted on our detecting a pattern in preferences. Interestingly, Little, DeBruine, and Jones (2014) reported that following experimentally familiarizing participants to a set of faces, men preferred the faces of unfamiliar over familiar females. In another study, the attractiveness of men's facial hair was found to vary with the frequency of certain facial hair quantities, so that beards became more attractive when beards were rare and less attractive when they were common (Janif et al. 2014). Thus, there is evidence that rarity and negative frequency-dependence could underpin preferences for female faces (Little et al. 2014) and cutaneous traits like beards in men (Janif et al. 2014), but using similar techniques we were unable to show similar patterns for women's hair color.

It is possible that rather than effects of experimentally familiarizing participants to a distribution of hair colors in a population, frequency-dependent preferences for hair color are better understood within context of the proportion of hair color from which the sample population was derived. Hinsz et al. (2013) measured preferences for hair color against the frequency of hair color in two samples from Northern and Southern prairies in North Dakota, U.S.A and found positive selection for brown hair when brown hair was common in the population. Unfortunately we are unable to determine the frequency of hair color in the local population to the same resolution as in Hinsz et al. (2013), given the large geographic range of our Internet sample of participants. However, we were able to test whether absolute preferences for hair color are mediated by relative factors such as participants' own hair color and their partners hair color (Bovet et al. 2012; Hinsz et al. 2013), which could, in turn, influence frequencydependent preferences for hair color. Homogamy, the degree to which a mate bares selfresembling characteristics, has been shown to predict preferences for hair color and preferences within couples (Bovet et al. 2012). We found that self-reported hair color interacted with treatment and ethnicity to determine hair color preferences. However, this relationship was driven by participants of non-European with red hair giving lower ratings for some hair colors in treatments in which red hair was rare. While this could be an artifact of cross-cultural variability in hair color preferences (Swami et al. 2008), many of the non-European participants who completed this study were of Asian descent. In these populations participants naturally occurring rates of red hair may be 
low, which could have influenced ratings. Interestingly, when the sample was restricted to participants of European descent, preferences for red hair were higher among participants with red hair within treatments wherein brown hair was rare and red hair was more common. Future cross-cultural studies quantifying in more detail the frequency-dependent preferences, particularly among Scandinavian and other European countries where hair color is polymorphic, for hair color would be valuable as an extension of our findings.

Similarly to Hinsz et al. (2013), we found sex differences in attractiveness ratings of women's hair color. Women preferred blond and brown hair equally, and rated them more attractive, on average, than red heads. In contrast, men rated blond hair as significantly more attractive than brown hair, and rated red hair least attractive. There are several ways to interpret these findings. One theory suggests men's preferences for lighter hair reflects selection for cues of youth, health, and even fertility in hair quality (Hinsz et al. 2001; Fink et al. 2013). Blond hair has been argued to amplify skin complexion as a signal of underlying disease resistance, making it easier for men to detect diseases than among women with darker hair and more melanic skin complexions (Ramachandran 1997). Indeed, some studies have found blond hair to be rated as most attractive (Sorokowski 2006), healthier, and more youthful than brown hair (Sorokowski 2008). However, numerous studies have found that brown hair is rated more favorably than blond hair (Swami, Furnham and Joshi 2008; Swami et al. 2008; Swami and Barrett 2011; Sorokowski 2008). Empirically demonstrating that men's preferences are influenced by current health in blond haired than darker haired women would certainly be valuable to determine.

As in studies testing for frequency-dependence in attractiveness ratings for women's hair color, the equivocal nature of findings from previous studies and those of the present study may be due, in part, to the differing methodologies employed to manipulate hair color to test men's preferences. For example, methods range from written surveys (Hinsz et al. 2013; Verweij, Burri, and Zietsch 2012), line drawings (Swami, Furnham and Joshi 2008; Swami et al. 2008), computer manipulations of hair color (Sorokowski 2008), wigs (Guéguen 2012a,b), and one confederate rated with artificially dyed red, brown or blond hair (Swami and Barrett 2011). While the use of computer-generated stimuli allows for the role of traits to be studied in isolation from surrounding traits, this method may be problematic. Eyebrow color, eye color, and skin complexion all vary with hair color. Thus, naturally occurring red hair is typically associated with lighter skin, freckles, and possibly lighter eyebrows, whereas skin complexion is typically more melanic among people with darker hair. As such, manipulating hair color alone as we did in our stimuli may have created a mismatch between other facial traits and hair color. Finally, we measured hair color preferences against partners hair color by asking individuals to state their partners natural hair color, which did not account for the possibility that participant's partners were dying their hair. Thus, while Bovet et al. (2012) found concordance in preferences for hair color between natural and computer-generated stimuli, our results may still have been influenced by using digitally manipulated images to measure preferences and future studies replicating our findings using natural stimuli would certainly be valuable.

Preferences for various aspects of facial morphology are positively associated with women's actual partners. For example, preferences for more masculine faces are higher among women with more facially masculine partners (Debruine et al. 2006), and 
preferences for beards are higher among women with more bearded partners (Dixson, Tam, and Awasthy 2013). Men's preferences for women's hair color may also reflect actual preferences (Bovet et al. 2012) or be associated with preferences for rare hair colors as men prefer unfamiliar over familiar female faces (Little et al. 2014). However, we found no effect of partners hair color on men's preferences for hair colors. Further, men's partners hair color did not result in significant effects of frequency dependence on preferences for hair color. For the present, our study provides no support for negative frequency-dependence acting on preferences for women's hair color. Given that hair color is a highly polymorphic character subject to cultural variation, further cross-cultural extensions of this study would be valuable.

\section{References}

Andersson, M. B. (1994). Sexual selection. Princeton: Princeton University Press.

Aoki, K. (2002). Sexual selection as a cause of human skin color variation: Darwin's hypothesis revisited. Annals of Human Biology, 29, 589-608.

Bakker, T., \& Pomiankowski, A. (1995). The genetic basis of female mate preferences. Journal of Evolutionary Biology, 8, 129-171.

Beleza, S., Santos, A. M., McEvoy, B., Alves, I., Martinho, C., Cameron, E., Shriver, M. D., Parra, E. J., \& Rocha, J. (2013). The timing of pigmentation lightening in Europeans. Molecular Biology and Evolution, 30, 24-35.

Bovet, J., Barthes, J., Durand, V., Raymond, M., \& Alvergne, A. (2012). Men's preference for women's facial features: Testing homogamy and the paternity uncertainty hypothesis. PloS One, 7(11), e49791.

DeBruine, L. M., Jones, B. C., Little, A. C., Boothroyd, L. G., Perrett, D. I., Penton-Voak, I. S., Cooper, P. A., Penke, L., Feinberg, D. R., \& Tiddeman, B. P. (2006). Correlated preferences for facial masculinity and ideal or actual partners masculinity. Proceedings of the Royal Society B: Biological Sciences, 273, 1355-1360.

Dixson, B. J., Dixson, A. F., Li, B., \& Anderson, M. J. (2007a). Studies of human physique and sexual attractiveness: Sexual preferences of men and women in China. American Journal of Human Biology, 19, 88-95.

Dixson, B. J., Dixson, A. F., Morgan, B., \& Anderson, M. J. (2007b). Human physique and sexual attractiveness: Sexual preferences of men and women in Bakossiland, Cameroon. Archives of Sexual Behavior, 36, 369-375.

Dixson, B. J., Dixson, A. F., Bishop, P., \& Parish, A. (2010). Human physique and sexual attractiveness in men and women: A New Zealand-U.S. comparative study. Archives of Sexual Behavior, 39, 798-806.

Dixson, B. J., Tam, J. C., \& Awasthy, M. (2013). Do women's preferences for men's facial hair change with reproductive status? Behavioral Ecology, 24, 708-716.

Farr, J. A. (1977). Male rarity or novelty, female choice behavior, and sexual selection in the guppy, Poecilia reticulata Peters (Pisces: Poeciliidae). Evolution, 162-168.

Fink, B., Neuser, F., Deloux, G., Röder, S., \& Matts, P. J. (2013). Visual attention to and perception of undamaged and damaged versions of natural and colored female hair. Journal of Cosmetic Dermatology, $12,78-84$.

Frost, P. (2006). European hair and eye color: A case of frequency-dependent sexual selection? Evolution and Human Behavior, 27, 85-103.

Frost, P. (2014). The puzzle of European hair, eye, and skin color. Advances in Anthropology, 4, $78-88$.

Gray, J. (2008). Human hair. In A. J. McMichael \& M. K. Hordinsky (Eds.), Hair and scalp diseases: Medical, surgical, and cosmetic treatments (pp. 1-19). London: Taylor and Francis.

Guéguen, N. (2012a). Hair color and wages: Waitresses with blond hair have more fun. Journal of SocioEconomics.

Guéguen, N. (2012b). Hair color and courtship: Blond women received more courtship solicitations and redhead men received more refusals. Psychological Studies, 57, 369-375. 
Gutierres, S. E., Kenrick, D. T., \& Partch, J. J. (1999). Beauty, dominance, and the mating game: Contrast effects in self-assessment reflect gender differences in mate selection. Personality and Social Psychology Bulletin, 25, 1126-1134.

Harding, R. M., Healy, E., Ray, A. J., Ellis, N. S., Flanagan, N., Todd, C., Sajantila, A., Jackson, I. J., BirchMachin, M. A., \& Rees, J. L. (2000). Evidence for variable selective pressures at MC1R. The American Journal of Human Genetics, 66, 1351-1361.

Heckert, D. M., \& Best, A. (1997). Ugly duckling to swan: labeling theory and the stigmatization of red hair. Symbolic Interaction, 20, 365-384.

Hine, E., Chenoweth, S. F., \& Blows, M. W. (2004). Multivariate quantitative genetics and the lek paradox: genetic variance in male sexually selected traits of Drosophila serrata under field conditions. Evolution, 58, 2754-2762.

Hinsz, V. B., Matz, D. C., \& Patience, R. A. (2001). Does women's hair signal reproductive potential? Journal of Experimental Social Psychology, 37(2), 166-172.

Hinsz, V. B., Stoesser, C. J., \& Matz, D. C. (2013). The intermingling of social and evolutionary psychology influences on hair color preferences. Current Psychology, 1-14.

Houde, A. E. (1997). Sex, color and mate choice in Guppies. Princeton: Princeton University Press.

Hughes, K. A., Du, L., Rodd, F. H., \& Reznick, D. N. (1999). Familiarity leads to female mate preference for novel males in the guppy, (Poecilia reticulate). Animal Behaviour, 58, 907-916.

Hughes, K. A., Houde, A. E., Price, A. C., \& Rodd, F. H. (2013). Mating advantage for rare males in wild guppy populations. Nature, 503, 108-110.

Jablonski, N. G., \& Chaplin, G. (2000). The evolution of human skin coloration. Journal of Human Evolution, $39,57-106$.

Jablonski, N. G., \& Chaplin, G. (2010). Human skin pigmentation as an adaptation to UV radiation. Proceedings of the National Academy of Sciences, 107, 8962-8968.

Jablonski, N. G., \& Chaplin, G. (2014). The evolution of skin pigmentation and hair texture in people of African ancestry. Dermatologic Clinics, 32, 113-121.

Janif, Z. J., Brooks, R. C., \& Dixson, B. J. (2014). Negative frequency-dependent preferences and variation in male facial hair. Biology Letters, 10, 20130958.

Kelley, J. L., Graves, J. A., \& Magurran, A. E. (1999). Familiarity breeds contempt in guppies. Nature, 401, $661-662$.

Kinsey, A. C., Pomeroy, W. B., \& Martin, C. E. (1948). Sexual behavior in the human male. Philadelphia: Saunders.

Kirkpatrick, M., \& Ryan, M. J. (1991). The evolution of mating preferences and the paradox of the lek. Nature, 350, 33-38.

Kokko, H., Jennions, M. D., \& Houde, A. (2007). Evolution of frequency-dependent mate choice: Keeping up with fashion trends. Proceedings of the Royal Society B: Biological Sciences, 274, 1317-1324.

Little, A. C., DeBruine, L. M., \& Jones, B. C. (2005). Sex-contingent face after-effects suggest distinct neural populations code male and female faces. Proceedings of the Royal Society B: Biological Sciences, 272, 2283-2287.

Little, A. C., DeBruine, L. M., \& Jones, B. C. (2014). Sex Differences in attraction to familiar and unfamiliar opposite sex faces: Men prefer novelty and women prefer familiarity. Archives of Sexual Behavior, 43, 973-981.

Liu, F., Wen, B., \& Kayser, M. (2013). Colorful DNA polymorphisms in humans. Seminars in cell \& developmental biology.

Lynn, M. (2009). Determinants and consequences of female attractiveness and sexiness: Realistic tests with restaurant waitresses. Archives of Sexual Behavior, 38, 737-745.

Madrigal, L., \& Kelly, W. (2007). Human skin color sexual dimorphism: A test of the sexual selection hypothesis. American Journal of Physical Anthropology, 132, 470-482.

Matz, D. C., \& Hinsz, V. B. (2000). Many gentlemen do not prefer blonds: perceptions of, and preferences for, women's hair color. In 1st meeting of the Society for Personality and Social Psychology, Nashville, Tennessee (pp. 3-6).

Olendorf, R., Rodd, F. H., Punzalan, D., Houde, A. E., Hurt, C., Reznick, D. N., \& Hughes, K. A. (2006). Frequency dependent survival in natural guppy populations. Nature, 44, 633-636.

Principe, C. P., \& Langlois, J. H. (2012). Shifting the prototype: Experience with faces influences affective and attractiveness preferences. Social Cognition, 30, 109-120.

Ramachandran, V. S. (1997). Why do gentlemen prefer blondes? Medical Hypotheses, 48, 19-20.

Rich, M. K., \& Cash, T. F. (1993). The American image of beauty: Media representations of hair color for four decades. Sex Roles, 29, 113-124.

Robins, A. H. (1991). Biological perspectives on human pigmentation. Cambridge: Cambridge University Press. 
Rosenqvist, G., \& Houde, A. (1997). Prior exposure to male phenotypes influences mate choice in the guppy, Poecilia reticulata. Behavioral Ecology, 8, 194-198.

Rowe, L., \& Houle, D. (1996). The lek paradox and the capture of genetic variance by condition dependent traits. Proceedings of the Royal Society of London. Series B, 263, 1415-1421.

Schweder, B. I. M. (1994). The impact of the face on long-term human relationships. Homo, 45, 74-93.

Sorokowski, P. (2006). Do men prefer blonde women? The influence of hair color on the perception of age and attractiveness of women. Studia Psychologiczne (Psychological Studies), 44, 77-88.

Sorokowski, P. (2008). Attractiveness of blonde women in evolutionary perspective: Studies with two Polish samples. Perceptual and Motor Skills, 106(3), 737-744.

Sorokowski, P., Sorokowska, A., \& Kras, D. (2013). Face color and sexual attractiveness: Preferences of Yali people of Papua. Cross-Cultural Research.

Swami, V., \& Barrett, S. (2011). British men's hair color preferences: An assessment of courtship solicitation and stimulus ratings. Scandinavian Journal of Psychology, 52, 595-600.

Swami, V., Furnham, A., \& Joshi, K. (2008a). The influence of skin tone, hair length, and hair color on ratings of women's physical attractiveness, health and fertility. Scandinavian Journal of Psychology, 49, 429-437.

Swami, V., Rozmus-Wrzesinska, M., Voracek, M., Haubner, T., Danel, D., Pawłowski, B., \& Furnham, A. (2008b). The influence of skin tone, body weight, and hair color on perceptions of women's attractiveness and health: A cross-cultural investigation. Journal of Evolutionary Psychology, 6(4), 321-341.

Templeton, A. (2002). Out of Africa again and again. Nature, 416, 45-51.

Thelen, T. H. (1983). Minority type human mate preference. Biodemography and Social Biology, 30, 162-180.

Van den Berghe, P. L., \& Frost, P. (1986). Skin color preference, sexual dimorphism and sexual selection: A case of gene culture co-evolution? Ethnic and Racial Studies, 9, 87-113.

Verweij, K. J., Burri, A. V., \& Zietsch, B. P. (2012). Evidence for genetic variation in human mate preferences for sexually dimorphic physical traits. PloS One, 7(11), e49294.

Wilde, S., Timpson, A., Kirsanow, K., Kaiser, E., Kayser, M., Unterländer, M., Holfelder, N., Potekhina, I. D., Schier, W., Thoma, M. G., \& Burger, J. (2014). Direct evidence for positive selection of skin, hair, and eye pigmentation in Europeans during the last 5,000 y. Proceedings of the National Academy of Sciences, $111,4832-4837$.

Zajitschek, S. R., \& Brooks, R. C. (2008). Distinguishing the effects of familiarity, relatedness, and color pattern rarity on attractiveness and measuring their effects on sexual selection in guppies (Poecilia reticulata). The American Naturalist, 172, 843-854. 